\title{
A remineralização de solos como iniciativa ao desenvolvimento sustentável
}

\author{
Soill remineralization as an initiative for sustainable development \\ La remineralización del suelo como iniciativa para el desarrolo sostenible
}

Recebido: 07/10/2021 | Revisado: 1610/2021 | Aceito: 22/10/2021 | Publicado: 24/10/2021

\author{
Lilian Sofia de Barros Viana \\ ORCID: https://orcid.org/0000-0002-6580-0389 \\ Universidade Federal do Pará, Brasil \\ E-mail: 1viana.viana@yahoo.com.br \\ Thamires Beatriz dos Santos Caitano \\ ORCID: https://orcid.org/0000-0002-7538-4366 \\ Universidade do Estado do Pará, Brasil \\ E-mail: thamirescaitano@hotmail.com \\ Altem Nascimento Pontes \\ ORCID: https://orcid.org/0000-0002-9001-4603 \\ Universidade do Estado do Pará, Brasil \\ E-mail: altempontes@hotmail.com
}

\begin{abstract}
Resumo
O Brasil é um país agrícola e extremamente dependente de fertilizantes químicos oriundos do mercado internacional. A remineralização de solos é uma importante solução para recuperação dos nutrientes de terrenos submetidos a cultivo intenso ou processo de intemperismo e lixiviação, principalmente em regiões tropicais. Sendo assim, o objetivo do artigo foi demonstrar a importância dos remineralizadores como uma alternativa sustentável de fertilização de solos no Brasil, por meio de uma revisão bibliográfica, análise da legislação vigente e de dados públicos oficiais. A Lei 12.890/2013 incluiu os remineralizadores como uma categoria de insumo destinado à agricultura e a Instrução Normativa no 05/2016 publicada pelo Ministério da Agricultura, Pecuária e Abastecimento (MAPA) regulamentou esse novo insumo agrícola. As pesquisas e empregos das técnicas de rochagem têm aumentado, inclusive com registro no MAPA de empresas produtoras de remineralizadores em alguns estados brasileiros, como Minas Gerais, Goiás e Paraná. E embora o Pará tenha destaque nacional na produção mineral, ainda não há registro de produção desse insumo no estado, o que torna necessário desenvolver pesquisas de aproveitamento de pó de rochas na região. A técnica de rochagem traz benefícios como custos significativamente menores do que os fertilizantes convencionais; aumento da produção agrícola; ausência de impactos ambientais ao solo e corpos d'água; além do aproveitamento de resíduos minerais. Considerando a geodiversidade brasileira, os remineralizadores tendem a se converter em um insumo agrícola de grande disponibilidade no país, permitindo a diminuição da sua dependência externa de fertilizantes, trazendo benefícios sociais, econômicos, produtivos e ambientais ao país.
\end{abstract}

Palavras-chave: Remineralizador; Agricultura; Sustentabilidade.

\begin{abstract}
Brazil is an agricultural country and extremely dependent on chemical fertilizers from the international market. Soil remineralization is an important solution for nutrient recovery from land subjected to intense cultivation or weathering and leaching processes, especially in tropical regions. Thus, the objective of this article was to demonstrate the importance of remineralizers as a sustainable alternative for soil fertilization in Brazil, through a bibliographical review, analysis of the current legislation and official public data. Law 12,890/2013 included remineralizers as a category of input for agriculture and Normative Instruction No. 05/2016 published by the Ministry of Agriculture, Livestock and Supply (MAPA) regulated this new agricultural input. The research and employment of rockstone techniques has increased, including registration in the MAPA of companies producing remineralizers in some Brazilian states, such as Minas Gerais, Goiás and Paraná. And although Pará has national prominence in mineral production, there is still no record of production of this input in the state, which makes it necessary to develop research into the use of rock powder in the region. The stonemeal technique brings benefits such as significantly lower costs than conventional fertilizers; increased agricultural production; absence of environmental impacts to the soil and water bodies; in addition to the use of mineral residues. Considering the Brazilian geodiversity, remineralizers tend to become an agricultural input of great availability in the country, allowing the reduction of its external dependence on fertilizers, bringing social, economic, productive and environmental benefits to the country.
\end{abstract}

Keywords: Remineralizer; Agriculture; Sustainability. 


\begin{abstract}
Resumen
El Brasil es un país agrícola y extremadamente dependiente de los fertilizantes químicos del mercado internacional. La remineralización del suelo es una solución importante para la recuperación de nutrientes de tierras sometidas a intensos procesos de cultivo o meteorización y lixiviación, especialmente en las regiones tropicales. Así, el objetivo del artículo fue demostrar la importancia de los remineralizantes como alternativa sostenible para la fertilización del suelo en Brasil, a través de una revisión de la literatura, análisis de la legislación vigente y datos públicos oficiales. La Ley 12.890 / 2013 incluyó los remineralizadores como categoría de insumo para la agricultura y la Instrucción Normativa No. 05/2016 publicada por el Ministerio de Agricultura, Ganadería y Abastecimiento (MAPA) reguló este nuevo insumo agrícola. Se ha aumentado la investigación y el uso de técnicas de polvo de roca, incluyendo con el registro en el MAPA de empresas productoras de remineralizantes en algunos estados brasileños, como Minas Gerais, Goiás y Paraná. Y aunque Pará tiene prominencia nacional en la producción de minerales, aún no hay registro de producción de este insumo en el estado, lo que hace necesario desarrollar investigaciones sobre el uso de polvo de roca en la región. La técnica de remineralización traer beneficios tales como costos significativamente más bajos que los fertilizantes convencionales; aumento de la producción agrícola; ausencia de impactos ambientales al suelo y cuerpos de agua; además del uso de residuos minerales. Considerando la geodiversidad brasileña, los remineralizadores tienden a convertirse en un insumo agrícola de amplia disponibilidad en el país, permitiendo la reducción de su dependencia externa de fertilizantes, trayendo beneficios sociales, económicos, productivos y ambientales al país.
\end{abstract}

Palabras clave: Remineralizador; Agricultura; Sustentabilidad.

\title{
1. Introdução
}

O Brasil tem se firmado cada vez mais em uma economia de base agroexportadora, onde os ganhos na produção de commodities agrícolas deverão ser um dos principais fatores de crescimento nos próximos anos (MAPA, 2021). Percebe-se assim que, à medida que a produção agrícola cresce, a demanda por fertilizantes químicos torna-se cada vez maior, em especial em solos tropicais, onde a disposição de nutrientes tende a ser menor (Souza, 2014). No entanto, a maioria dos insumos agrícolas precisam ser importados devido à falta de abastecimento no mercado interno (Oliveira et al., 2019).

Sendo assim, o Brasil é dependente de fertilizantes convencionais, cuja matéria-prima é em grande parte oriunda de outros países, tendo como principais componentes químicos o nitrogênio, o fósforo e o potássio, os chamados NPK (ANDA, 2021). Atualmente, os Estados Unidos, a Rússia, o Canadá e o Marrocos detêm as principais jazidas dos minerais utilizados para as formulações NPK (Theodoro et al., 2012).

A dependência da importação de produtos químicos fertilizantes de solo no país é superior a 90\%, sendo que apenas em 2020, o Brasil importou US\$ 8.027.715.871 bilhões em fertilizantes, o que corresponde a mais de 34 MT (MDIC, 2021). Este dado é preocupante, pois em um cenário de crise de alguns dos países exportadores, o Brasil pode ser afetado, tanto em relação ao seu abastecimento interno de produtos agrícolas, como nas exportações, já que este é considerado um player mundial no fornecimento de commodities agrícolas.

Em vista disso, busca-se mitigar a dependência do mercado externo, através da técnica de remineralização do solo, com o uso de agrominerais, devido ser uma importante fonte para a recuperação dos nutrientes de determinado terreno em processo de intemperismo e/ou lixiviação, com tecnologia mais sustentável, além de permitir incremento de renda e de segurança alimentar e nutricional, sendo uma importante inciativa ao desenvolvimento sustentável dentro do setor agrícola em países tropicais (Theodoro et al., 2012).

No Brasil, a previsão legal dos remineralizadores de solos ocorreu no ano de 2013, por meio da Lei Complementar $n^{\circ}$ 12.890, 10 de dezembro de 2013, a qual alterou a Lei dos Fertilizantes (Lei n ${ }^{\circ}$ 6.894/1980) que dispõe sobre a fiscalização da produção e comércio de fertilizantes que deve ser realizada pelo Ministério da Agricultura, Pecuária e Abastecimento (MAPA), cujo órgão pertence à União. A Lei $\mathrm{n}^{\circ}$ 12.890/2013 incluiu uma nova categoria de insumo agrícola: os remineralizadores, também conhecidos como pós de rochas.

Esta Lei define remineralizador como um material de origem mineral que tenha sido submetido a redução e classificação de tamanho por processos mecânicos e que altere os índices de fertilidade do solo por meio da adição de macro e 
micronutrientes para as plantas, bem como promova a melhoria das propriedades físicas ou físico-químicas ou da atividade biológica do solo (Brasil, 2013). Dessa forma, os remineralizadores de solos podem ser oriundos de rochas de diversas origens e composições químicas.

O Plano Nacional de Mineração - PNM 2030, apresenta a sustentabilidade no setor mineral brasileiro como uma de suas diretrizes, o que reforça a prática da reutilização do pó de rocha na agricultura (MME, 2011). Da mesma forma, a Política Nacional de Resíduos Sólidos, adota o princípio do desenvolvimento sustentável para os resíduos de mineração gerados na atividade de pesquisa, extração ou beneficiamento de minérios (Brasil, 2010).

Nesse sentido, muitos estudos têm sido voltados à avaliação do potencial de uso de rochas silicáticas no suprimento de nutrientes em cultivos agrícolas, a exemplo dos granitos, que geram resíduos nas pedreiras e podem ser utilizados nesse segmento econômico como uma fonte de nutrientes na agricultura tropical (Souza, 2014). Desta forma, busca-se um fim sustentável a esses resíduos minerais através do reaproveitamento, dada sua disponibilidade elevada em muitas minas (Carvalho et al., 2018).

Ademais, vários órgãos, dentre os quais, o Serviço Geológico do Brasil (CPRM) e a Empresa Brasileira de Pesquisa Agropecuária (EMBRAPA), trabalham em projetos para pesquisas de áreas produtoras e consumidoras de agrominerais no país (CPRM, 2020; Bamberg et al., 2016). Além disso, algumas empresas no Brasil já utilizam a técnica de rochagem, tendo em vista sua relevância na fertilização de solos agrícolas.

A rochagem é de fundamental importância para o meio ambiente, para o agronegócio, em especial para a agricultura familiar, por ser uma atividade de menor risco financeiro e que diminui a dependência das importações de fertilizantes químicos (Bergmann et al., 2011). O pó de rocha libera nutrientes de forma mais lenta, o que oferece vantagens, como o maior tempo de permanência de nutrientes no solo em relação aos fertilizantes químicos (Theodoro \& Leonardos, 2006).

Além disso, essa técnica traz benefícios na redução dos custos produtivos, no aumento da produção agrícola, consequentemente na melhora dos resultados econômicos e evita impactos ambientais causados pelos fertilizantes químicos, como a poluição dos solos e dos recursos hídricos (Silva et al., 2020). Sendo assim, a remineralização do solo é um assunto que requer atenção especial, face à sua relevância econômica, social e ambiental.

Diante do exposto, este trabalho tem como objetivo demonstrar a importância dos remineralizadores como uma alternativa sustentável de fertilização de solos no Brasil, enfatizando as questões legais, empresas produtoras, casos de sucesso de remineralização de solos agrícolas, aspectos socioeconômicos e ambientais da técnica de rochagem e suas implicações no futuro do agronegócio brasileiro.

\section{Metodologia}

Os procedimentos metodológicos envolveram revisão bibliográfica, com as contribuições de diversos autores, bem como estudos de caso, em consonância com as regulamentações vigentes, o conhecimento técnico e a aplicação de métodos de sustentabilidade (Theodoro et al., 2012; Souza, 2014; Oliveira et al., 2019). A fim de alcançar o objeto do estudo, foram realizadas pesquisas em sites oficiais do governo brasileiro, como o Ministério de Agricultura, Pecuária e Abastecimento (MAPA) e o Ministério de Desenvolvimento da Indústria e Comércio (MDIC), e ainda coleta e análise de dados do Instituto Brasil Orgânico e da Associação Nacional para Difusão de Adubos (ANDA).

Além disso, foram realizadas consultas aos dispositivos legais que envolvem a fiscalização da produção e comércio de fertilizantes, como a Lei ${ }^{\circ}$ 6.894/1980; Lei $n^{\circ} 12.890 / 2013$, a qual altera a Lei $n^{\circ}$ 6.894/1980; Decreto $n^{\circ}$ 4954/2004 alterado pelo Decreto no 8.384/2014 e Instruções Normativas 5 e 6/2016 do MAPA. Também foi confeccionado o mapa de localização das empresas produtoras de remineralizadores de solos no Brasil utilizando os softwares ArcMap 10.5 e Google Earth PRO. 


\section{Resultados e Discussão}

\subsection{Aspectos Legais dos Remineralizadores no Brasil}

O Ministério da Agricultura, Pecuária e Abastecimento (MAPA) é o órgão federal responsável pela regulamentação da produção e do comércio de fertilizantes, corretivos, inoculantes e biofertilizantes no Brasil, sendo composta por um conjunto de leis, decretos, instruções normativas, portarias e normas internas. A legislação atual acerca dos fertilizantes está baseada na Lei 6.894/80, que dispõe sobre a inspeção e fiscalização da produção e do comércio dos insumos destinados à agricultura no país, e determina a competência do MAPA para realizar a fiscalização e a obrigatoriedade do registro das empresas e de seus produtos.

A alteração da Lei dos Fertilizantes a partir da Lei 12.890/ 2013, foi um passo importante na implantação do marco legal que permite a comercialização e o uso dos remineralizadores de solos no Brasil, já que estes passam a ser reconhecidos como uma categoria de insumo destinado à agricultura, assim como os fertilizantes convencionais. Esta Lei tem como propósito aumentar de maneira sustentável a produtividade agrícola do país e garantir a segurança e soberania alimentar (Brasil, 2013).

O Decreto $n^{\circ} 4.954 / 2004$, alterado pelo Decreto $n^{\circ} 8.384 / 2014$, regulamenta a Lei $n^{\circ} 6.894 / 1980$ estabelecendo as normas gerais sobre registro, padronização, classificação e fiscalização da produção e do comércio de fertilizantes, corretivos, inoculantes, biofertilizantes, remineralizadores e substratos para plantas destinados à agricultura. O Decreto determina que os estabelecimentos que produzem, comercializam, exportam ou importam remineralizadores ficam obrigados a se registrar no MAPA (Brasil, 2014).

Em seu Art. $2^{\circ}$, inciso XIV, define e classifica os nutrientes em três tipos: macronutrientes primários (Nitrogênio, Fósforo e Potássio- NPK, expressos nas formas de Nitrogênio-N, Peróxido de Fósforo- $\mathrm{P}_{2} \mathrm{O}_{5}$ e Óxido de Potássio- $\mathrm{K}_{2} \mathrm{O}$ ); macronutrientes secundários (Cálcio, Magnésio e Enxofre, expressos nas formas de Cálcio-Ca ou Óxido de Cálcio- $\mathrm{Ca}_{2} \mathrm{O}$, Magnésio - Mg ou Óxido de Magnésio - $\mathrm{Mg}_{2} \mathrm{O}$ e Enxofre -S) e micronutrientes (Boro-B, Cloro-Cl, Cobre-Cu, Manganês- $\mathrm{Mn}$, Ferro-Fe, Molibdênio -Mo, Zinco -Zn, Cobalto -Co, Silício -Si) e outros que vierem a ser definidos pela pesquisa científica (Brasil, 2014).

Os resultados obtidos pelos pesquisadores brasileiros sobre os benefícios do uso dos remineralizadores tiveram um papel fundamental na alteração do marco legal do setor de fertilizantes. Em 2016, o MAPA publicou as Instruções Normativas (INs) $\mathrm{n}^{\circ} 05$ e 06, que definiram as características permitidas e as garantias mínimas para os remineralizadores de solos no Brasil. A Figura 1 apresenta um resumo dos critérios para registro de remineralizadores de solos no MAPA.

A IN 5/2016 estabelece que para que seja assegurada a funcionalidade e tenha-se parâmetro de garantia, tais materiais deverão apresentar as seguintes características mínimas e máximas: mínimo de $9 \%$ de soma de bases e $1 \%$ de óxido de potássio; máximo de 15 ppm de Arsênio- As, 10 ppm de Cádmio- Cd, 0,1 ppm de Mercúrio- Hg e 200 ppm de Chumbo- Pb, e até $25 \%$ de $\mathrm{SiO}_{2}$ livre presente no produto. Outro fator importante é a comprovação da eficiência agronômica através de testes e pesquisa (Brasil, 2016). 
Figura 1. Fluxograma das etapas de avaliação para registro de remineralizadores no MAPA.

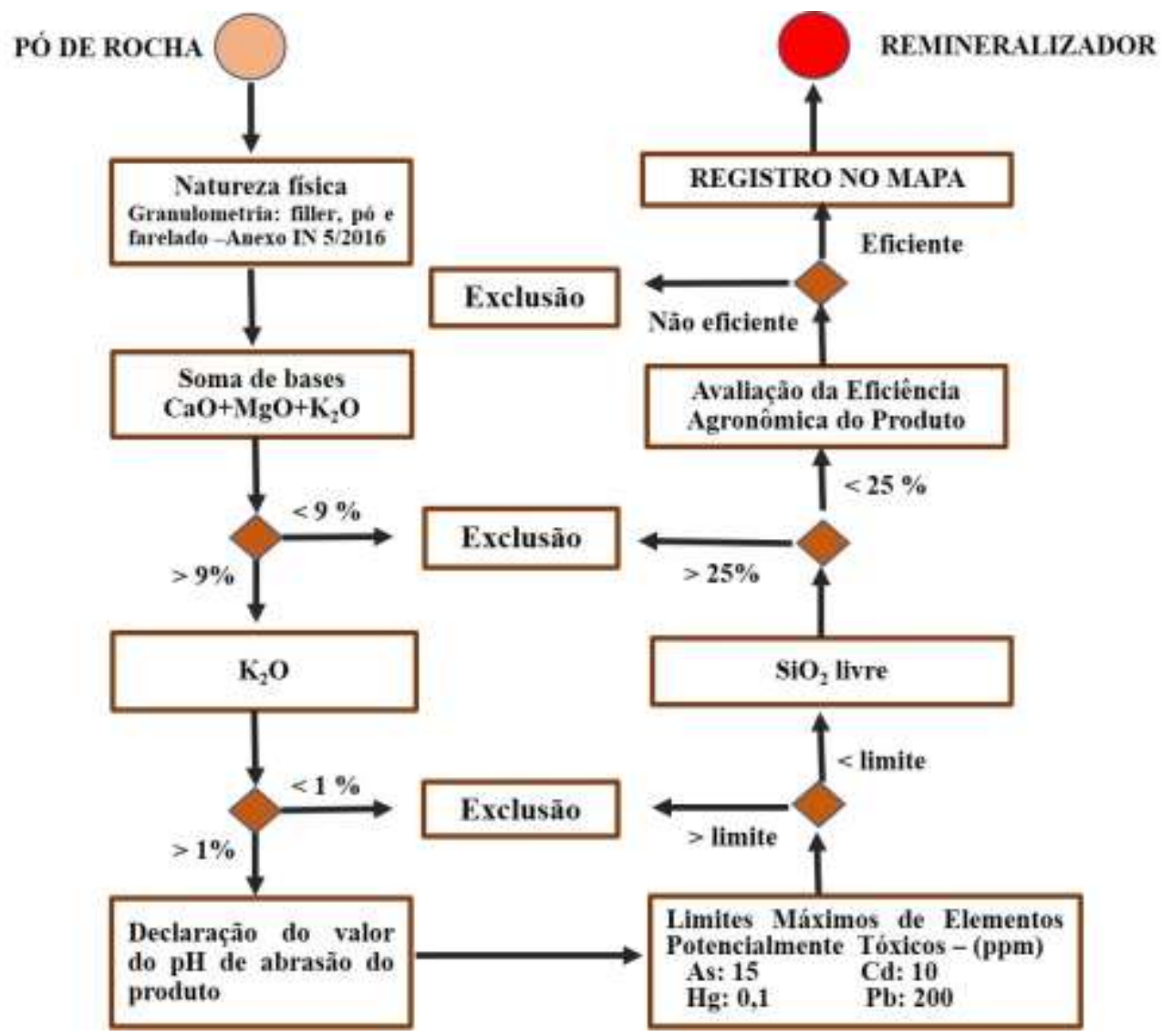

Fonte: Autores, adaptado da IN 5/2016.

Ademais, a IN 06/2016 estabelece que quando se tratar de remineralizadores, deve-se demonstrar que o produto atua isolada ou cumulativamente no crescimento, nas variáveis geoquímicas do solo e na produtividade da cultura. Estas normas possibilitaram o uso e a comercialização dos remineralizadores no país.

\subsection{Empresas Produtoras de Remineralizadores no Brasil}

Atualmente, no território brasileiro, existem 18 empresas que produzem remineralizadores registradas no MAPA (Figura 2). A maioria dessas empresas encontram-se no estado de Minas Gerais, o qual apresenta tradicionalmente uma economia mineira. Nota-se que no estado do Pará, não há nenhuma empresa registrada que atue na produção de remineralizadores de solo, apesar da contribuição mineral paraense na balança comercial brasileira ter sido superior ao do estado mineiro nos últimos 4 anos (MDIC, 2021).

A Tabela 1 apresenta as principais informações das empresas produtoras de remineralizadores de solo no país, algumas apresentam produtos obtido a partir da mistura de uma ou duas rochas, atendendo aos parâmetros e requisitos exigidos na Instrução Normativa 5/2016. 
Figura 2. Mapa de localização das empresas brasileiras com remineralizadores registrados no MAPA (27/07/2021).

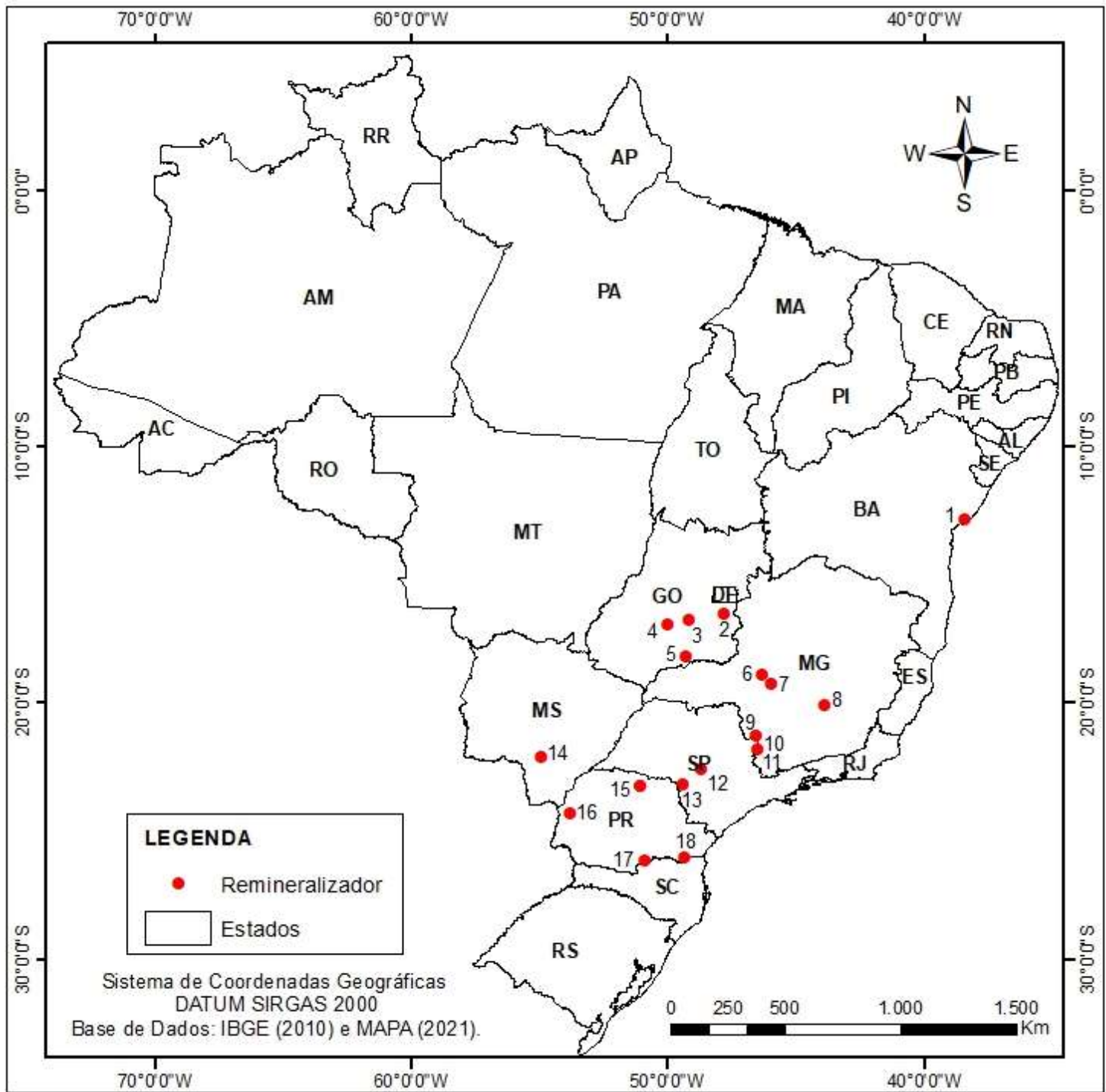

Fonte: Autores, adaptado de Instituto Brasil Orgânico (2021). 
Tabela 1. Descrição dos remineralizadores produzidos no Brasil conforme o registro no MAPA.

\begin{tabular}{|c|c|c|c|c|c|c|c|}
\hline & Nome da Empresa & Localização & Rocha & $\begin{array}{l}\text { \% Soma } \\
\text { de bases }\end{array}$ & $\begin{array}{c}\% \\
\mathrm{~K}_{2} \mathrm{O}\end{array}$ & $\begin{array}{c}\% \\
\mathrm{SiO}_{2}\end{array}$ & Nome comercial \\
\hline 1 & Civil Industrial e Comercial Ltda & Salvador - BA & Granulito & 9,9 & 3,9 & 17 & RMS-C01 \\
\hline 2 & $\begin{array}{l}\text { Mistel Mineração Santa } \\
\text { Terezinha Ltda }\end{array}$ & Luziânia- GO & Calcixisto & 23 & 2,7 & 20 & REMAX \\
\hline 3 & Pedreira Araguaia Ltda & $\begin{array}{l}\text { Aparecida de } \\
\text { Goiânia - GO }\end{array}$ & Micaxisto & 9,5 & 3,2 & 20 & FMX \\
\hline 4 & $\begin{array}{l}\text { Britago Mineração Indústria e } \\
\text { Comércio Ltda }\end{array}$ & $\begin{array}{l}\text { Santa Bárbara } \\
\text { de Goiás - GO }\end{array}$ & $\begin{array}{l}\text { Biotita } \\
\text { gnaisse } \\
\text { diorítico }\end{array}$ & 11 & 3 & $\mathrm{NI}^{*}$ & $\begin{array}{l}\text { Pó de Biotita gnaisse } \\
\text { diorito }\end{array}$ \\
\hline 5 & Goyaz Britas Ltda & Panamá - GO & Basalto & 11,5 & 3,5 & NI* & Pó de rocha Goyas \\
\hline 6 & Triunfo Mineração do Brasil Ltda & $\begin{array}{l}\text { Carmo do } \\
\text { Paranaíba-MG }\end{array}$ & Karmafugito & 11 & 3 & 0 & KP-Fértil \\
\hline 7 & Verde Fertilizantes Ltda & $\begin{array}{l}\text { São Gortado - } \\
\text { MG }\end{array}$ & $\begin{array}{l}\text { Siltito } \\
\text { glauconítico }\end{array}$ & 13 & 10 & 13 & K-Forte \\
\hline 8 & $\begin{array}{l}\text { Pedras Congonhas Extração Arte } \\
\text { Industria Limitada }\end{array}$ & $\begin{array}{l}\text { Nova Lima - } \\
\text { MG }\end{array}$ & $\begin{array}{l}\text { Serpentinito }+ \\
\text { Fonolito }\end{array}$ & 35 & 1 & 0 & - \\
\hline 9 & $\begin{array}{l}\text { BRITAMIL - Brita, Concreto e } \\
\text { Serviços de Engenharia Ltda }\end{array}$ & $\begin{array}{l}\text { Muzambinho - } \\
\text { MG }\end{array}$ & Anfibolito & 12,5 & 12 & 10 & - \\
\hline 10 & Mineração Curimbaba Ltda & $\begin{array}{l}\text { Poços de Caldas } \\
\text { - MG }\end{array}$ & Sienito & 12 & 12 & 0 & Potasil \\
\hline 11 & Mineração Curimbaba Ltda & $\begin{array}{l}\text { Poços de Caldas } \\
\text { - MG }\end{array}$ & Fonolito & 10 & 8 & 0 & Ekosil \\
\hline 12 & Pedreira Diabásio Ltda & $\begin{array}{l}\text { Lençóis Paulista } \\
\text { - SP }\end{array}$ & Diabásio & 14 & 1,4 & 0 & Reminer GS3 \\
\hline 13 & Pedreira Piraju Ltda & Piraju - SP & Dacito & 9 & 3,5 & 18 & Reminer K+ \\
\hline 14 & Mineração Tozzi Junqueira & Itaporã - MS & Basalto & 12,65 & 1,83 & 5 & - \\
\hline 15 & Pedreira ICA Ltda & Ibiporã - PR & Basalto & 12 & 1 & 0 & Pó de rocha ICA \\
\hline 16 & $\begin{array}{l}\text { MINERPAL Comércio de } \\
\text { Materiais e Pavimentacao Eireli }\end{array}$ & Palotina - PR & Basalto & 13 & 1,01 & 0 & Renutra \\
\hline 17 & $\begin{array}{l}\text { EKOSOLOS Indústria } \\
\text { Remineralizadora de Solos Ltda }\end{array}$ & $\begin{array}{l}\text { Paula Freitas - } \\
\text { PR }\end{array}$ & $\begin{array}{l}\text { Microgabro + } \\
\text { Dacito }\end{array}$ & 14 & 1,4 & 10 & Mineralle Agro \\
\hline 18 & BK Mineraçao Ltda & Pien - PR & $\begin{array}{l}\text { Serpentinito }+ \\
\text { Filito }\end{array}$ & 26 & 1,5 & 15 & Silmag \\
\hline
\end{tabular}

*NI: dados não informados.

Fonte: Instituto Brasil Orgânico (2021).

A Civil Mineração é uma das maiores pedreiras da Bahia, atua no setor da construção civil e na produção de remineralizadores, ofertando diversos produtos como pedra marroada, blocos de rocha, matacão, brita, areia de brita e pó de rocha advindo do granulito, que se diferenciam em relação à granulometria e finalidade de uso. Em termo de remineralizador, o granulito, rocha metamórfica composta basicamente por agrominerais silicáticos, em especial aluminossilicatos, traz resultados satisfatórios por possuir uma variedade de elementos químicos e com baixos teores, os quais auxiliam na nutrição e desenvolvimento da planta, e com solubilidade que melhoram a absorção radicular (EMBRAPA, 2020).

As pedreiras de Goiás comercializam agrominerais silicáticos, diferenciando-as em relação ao tipo de rocha explotada, sendo que a Mistel Mineração Santa Terezinha Ltda e a Pedreira Araguaia Ltda atuam exclusivamente no ramo da produção de remineralizadores. O pó de rocha do calcixisto (micaxisto carbonático) oriundo da Mistel é composto principalmente por $\mathrm{K}, \mathrm{Si}, \mathrm{Ca}$ e $\mathrm{Mg}$, e secundariamente, por $\mathrm{Zn}, \mathrm{B}, \mathrm{Mn}, \mathrm{Fe}, \mathrm{Cu}, \mathrm{S}$ e P. O silício traz diversos benefícios para a agricultura, como a neutralização do alumínio tóxico, a liberação do fósforo nativo do solo, o aumento da eficiência da adubação fosfatada, da disponibilidade do molibdênio, da atividade microbiana e a complexação de outros metais tóxicos.

No estado de Minas Gerais existem empresas que trabalham exclusivamente com o pó de rocha silicático para fins agronômicos, como a Triunfo Mineração do Brasil Ltda e a Verde Fertilizantes Ltda, sendo esta última explotadora do siltito glauconítico, constituído por metassedimentos pelíticos, com predominância de glauconita, quartzo, micas e outros minerais, 
contendo de 7 a 14\% de $\mathrm{K}_{2} \mathrm{O}$ (Piza et al., 2009). Diferente dos fertilizantes químicos, não possui $\mathrm{KCl}$ em sua composição, tendo assim baixa salinidade. Já a empresa Mineração Curimbaba Ltda possui diversas linhas de negócios, dentre as quais, a produção de remineralizadores de solos, e a empresa BRITAMIL reaproveita o pó de rocha para fins agrícolas.

As duas empresas localizadas em São Paulo trabalham no ramo da construção civil e no de remineralizadores, fazendo parte do mesmo grupo, ambas utilizam o pó de rocha silicático. A Mineração Tozzi Junqueira localizada no Mato Grosso do Sul desenvolve a produção de basalto voltada a atender o ramo da construção civil e do agronegócio. As demais empresas situam-se no Sul do Brasil, estado do Paraná, dentre as quais, a Pedreira ICA Ltda que utiliza o pó de rocha do basalto advindo da produção das britas da construção civil. O que ressalta a importância da sustentabilidade e da diminuição da dependência externa dos agrominerais, conceituados como minerais estratégicos, ou seja, aqueles considerados escassos, essenciais ou críticos para um país, dentro do Plano Nacional de Mineração 2030 (MME, 2021).

\subsection{Estudos de casos de sucesso de Remineralização de Solos Agrícolas}

Os estudos das técnicas de remineralização de solos demonstram diversas maneiras de aquisição de macro e micronutrientes na agricultura, pois deve-se levar em consideração o sistema rocha- planta- solo- clima (Souza, 2014). Por isso, as técnicas são variadas, como a utilização de pó de rocha associado a outro tipo de adubo, fertilizante ou condicionante, ou somente o uso do pó de rocha.

Uma das técnicas realizadas envolveu a associação de doses intermediárias de pó de basalto com doses maiores de esterco bovino, no trabalho intitulado "Produtividade do morangueiro em função da adubação orgânica e com pó de basalto no plantio", de Camargo et al. (2012), onde foram avaliados a produtividade, a produção comercial e a massa média do fruto.

O experimento ocorreu em Guarapuava, no estado do Paraná, no Setor de Olericultura da Unicentro, onde os frutos foram colhidos de outubro de 2008 a janeiro de 2009. Foram utilizados os tratamentos de 0,50 e $100 \mathrm{t} \mathrm{ha}^{-1}$ de esterco bovino e $0,2,4$ e $6 \mathrm{t} \mathrm{ha}^{-1}$ de pó de basalto. Os resultados obtidos mostraram que a massa média do fruto não apresentou diferença, no entanto, a produtividade e a produção comercial tiveram um melhor desempenho.

Outra aplicação de técnica de rochagem foi realizada na cultura do feijão preto, em Bom Progresso, no estado do Rio Grande do Sul, no trabalho desenvolvido por Silva et al. (2020), cujo tema foi "Pó de basalto como fertilizante alternativo na cultura do feijão preto em latossolo vermelho." O estudo demonstrou que o pó de basalto (PB) foi utilizado como fonte de nutrientes alternativo na cultura do feijão preto, na produção de matéria seca da parte aérea (MSPA) e de grãos de feijão preto em latossolo vermelho.

O experimento foi conduzido por dois anos, nas safras 2017/18 e 2018/19 em delineamento de blocos, com três repetições, totalizando 33 parcelas experimentais, constituídas de $6 \mathrm{~m}^{2}$ cada. Os tratamentos foram: 5, 10, 20, 40, 60, 80, 120, 160, $200 \mathrm{t} \mathrm{ha}^{-1}$ de PB; tratamento com fertilização química NPK e uma testemunha - TEST (sem PB e NPK). A semeadura do feijão preto foi com espaçamento de $40 \mathrm{~cm}$ entre linhas e $12 \mathrm{~cm}$ entre plantas.

A produção de MSPA e grãos de feijão apresentou tendência crescente em relação às doses de PB, ou seja, quanto maior a dose de PB, maior foi a produção de MSPA e grãos, com valores variando de 1091 a $2892 \mathrm{~kg} \mathrm{ha}^{-1} \mathrm{e} 989$ a $2111 \mathrm{~kg} \mathrm{ha}^{-1}$, respectivamente. Doses de 5 a $60 \mathrm{t} \mathrm{ha}^{-1}$ apresentam ação equivalente na produção MSPA e grãos de feijão preto em comparação com a fertilização química NPK. Doses de PB acima de $80 \mathrm{t}$ ha-1 promovem a maior produção de grãos de feijão preto em Latossolo vermelho (Silva et al., 2020).

No estudo de Crusciol e Soratto (2013), denominado "Eficiência de rocha fonolito moída como fonte de potássio para as culturas do arroz, feijão, milho e soja”, foi avaliada a eficácia da rocha Fonolito moída (F2) (procedentes da Mineração Curimbaba Ltda) como fonte de potássio e de silício para as culturas do arroz, milho, feijão e soja. A pesquisa foi realizada em Botucatu, no estado de São Paulo, na Fazenda Experimental Lageado, na safra verão 2007/2008, em um Latossolo Vermelho 
distroférrico. Os tratamentos, para todas as culturas, foram compostos por duas fontes de $\mathrm{K}$ (1- $\mathrm{KCl}-58 \%$ de $\mathrm{K}_{2} \mathrm{O}$ e $2-\mathrm{F} 2-$ $8,42 \%$ de $\left.\mathrm{K}_{2} \mathrm{O}\right)$ e quatro doses $\left(0,1 / 2,1\right.$ e 2 vezes a dose de $\left.\mathrm{K}_{2} \mathrm{O}\right)$ recomendada para as culturas.

A aplicação do produto $\mathrm{F} 2$ melhora a nutrição da cultura do arroz de sequeiro em $\mathrm{K} \mathrm{e} \mathrm{Si}$, proporciona incrementos na produtividade de grãos da ordem de $69 \%$ em relação ao controle, contudo o $\mathrm{KCl}$ proporcionou um aumento superior de $79 \%$ na produtividade de grãos. A aplicação do produto $\mathrm{F} 2$ melhora a nutrição da cultura de milho em $\mathrm{K}$ e $\mathrm{Si}$, proporciona incrementos na produtividade de grãos da ordem de 35,3 \% em relação ao controle, índice semelhante ao $\mathrm{KCl}(32,4 \%)$.

A aplicação do produto $\mathrm{F} 2$ melhora a nutrição da cultura do feijão em $\mathrm{K}$ e Si, porém reduz os teores de $\mathrm{N}$ sem, contudo, afetar o estado nutricional. Na cultura do feijão a aplicação do produto F2 proporciona incrementos na produtividade de grãos da ordem de $15 \%$ em relação ao controle, já o $\mathrm{KCl}$ proporcionou aumento de $25 \%$ na produtividade de grãos.

A aplicação do produto $\mathrm{F} 2$ bem como de $\mathrm{KCl}$ não altera o estado nutricional da cultura da soja, contudo proporciona incrementos na produtividade de grãos da ordem de $63,4 \%$, em relação ao controle, índice superior ao proporcionado pelo $\mathrm{KCl}$, que foi $58,0 \%$. Sendo assim, os resultados mostraram que quando utilizado na mesma dose de $\mathrm{K}_{2} \mathrm{O}$, esse produto aumenta os teores de $\mathrm{K}$ e Si nas culturas, o que resulta em aumento da produtividade de grãos, semelhante ao $\mathrm{KCl}$, que é a principal fonte de potássio utilizada no país (Crusciol \& Soratto, 2013).

Além disso, pesquisas têm demonstrado que a produção de grãos com o uso de pó de basalto em doses elevadas foi superior à testemunha e a forma de cultivo com o uso de fertilizantes químicos (Silva et al., 2020). Portanto, esses estudos de casos são exemplos da eficiência agronômica dos remineralizadores de solos no país.

\subsection{Aspectos socioeconômicos e ambientais da Prática de Rochagem}

$\mathrm{O}$ pó de rocha oferece uma maior diversidade de nutrientes para as plantas, o que reflete uma qualidade superior de nutrição também no solo, na vida vegetal e animal, diferente dos fertilizantes mais solúveis que são constituídos por apenas um ou alguns sais de alta pureza (Carvalho et al., 2018). A rocha moída possui liberação de nutrientes de forma lenta e contínua no solo, compensada pela disponibilização de multinutrientes e por um período de tempo mais longo (Theodoro, 2020). O pó de rocha é uma ótima opção para a agricultura familiar, pois possuem baixo custo, e evitam o êxodo rural, por vezes, causados pela manutenção dispendiosa da agricultura com uso de fertilizantes convencionais (Bergmann et al., 2011).

Além disso, a técnica de uso de pó de rocha melhora a situação econômico-financeira dos pequenos agricultores, devido ao custo de pó de rocha ser menor e seus efeitos de nutrição no solo são mantidos em média por 4 a 5 anos (Theodoro, 2000). Outro aspecto importante desse insumo, é que diminui a dependência das importações de fertilizantes químicos e consequentemente aumenta a segurança alimentar (Carvalho et al., 2018).

O Brasil tem uma expressiva geodiversidade, com diversos tipos de rochas em diferentes regiões do país que mostram resultados positivos nos níveis de fertilidade do solo e na produtividade, tornando o produto disponível (Theodoro, 2020). Do ponto de vista do transporte, o pó de rocha torna-se inviável economicamente quando a distância entre a mina e a propriedade agrícola for muita extensa, face a grande quantidade do produto demandada para uso (Souza, 2014).

O uso do pó de rocha favorece a supressão do passivo ambiental, o que tornam os espaços de estocagem livres para outro fim e dá destinação econômica ao estéril ou rejeito decorrente da atividade mineira (CPRM, 2020). Nesse sentido, a reutilização do material é uma grande vantagem do ponto de vista econômico e ambiental, pois o produtor comercializa o pó de rocha com os agricultores locais e, simultaneamente diminui o espaço físico antes ocupado pelas rochas remanescentes da produção mineral principal. 


\section{Considerações Finais}

Os estudos têm demonstrado que o cultivo de variados produtos agrícolas com a técnica de remineralização de solos apresentam resultados significativos, e a longo prazo superam a produtividade em relação a técnica de uso de fertilizantes químicos. Destaca-se sua importância econômica, que visa a redução dos custos de produção e o desenvolvimento de um mercado produtor interno; social, pois mantém as condições de trabalho no campo; e ambiental, haja vista que os agrominerais não poluem solos e rios, ao mesmo tempo em que diminuem o passivo ambiental das pedreiras.

O grande desafio é diminuir a dependência das importações de fertilizantes químicos que, se alcançado, proporcionará melhorias sob vários aspectos, de forma a aumentar as parcerias já existentes e os grupos de trabalho através de políticas públicas que visem novas descobertas e associações entre o uso de pó de rocha e as diversas culturas agrícolas. Para tanto, devem ser desenvolvidas pesquisas específicas de acordo com as características da rocha, do solo, do clima e do que se pretende cultivar.

Por fim, cabe ressaltar que o uso de pó de rocha na agricultura brasileira tem grande potencial, porém ainda pouco explorado, o que requer o desenvolvimento de mais pesquisas e estudos, principalmente de avaliação da eficiência agronômica de pós de rochas com aptidão para uso agrícola, sobretudo nos estados brasileiros que não apresentam remineralizadores registrados no MAPA, como por exemplo o estado do Pará, face a sua relevância de destaque no setor mineral.

\section{Referências}

ANDA. Associação Nacional para Difusão de Adubos (2021). Relatório sobre o Mercado de Fertilizantes. http://anda.org.br/pesquisa_setorial/

Bamberg, A. L., Silveira, C.A.P., Martins, E. S., Bergmann, M., Martinazzo, R. \& Theodoro, S. H. (2016). Anais do III Congresso Brasileiro de Rochagem. Embrapa Clima Temperado; Embrapa Cerrados. Triunfal (Ed), 455.

Bergmann, M., Theodoro, S. M de C. H. \& Hoff, R. (2011). Rochagem: uma alternativa sustentável na remineralização de solos. Embrapa Uva e Vinho (Infoteca-e). Conselho em Revista, 7 (85), 34-35.

Brasil. Decreto $n^{\circ} 8.384$, de 29 de dezembro de 2014 (2014). Altera o Anexo ao Decreto n $^{\circ} 4.954$, de 14 de janeiro de 2004 , que aprova o Regulamento da Lei $\mathrm{n}^{\circ}$ 6.894, de 16 de dezembro de 1980, que dispõe sobre a inspeção e fiscalização da produção e do comércio de fertilizantes, corretivos, inoculantes ou biofertilizantes destinados à agricultura. Diário Oficial da União, Brasília, DF, 10 dez 2014. http://www.planalto.gov.br/ccivil_03/_Ato20112014/2014/Decreto/D8384.htm\#art1

Brasil. Lei $n^{o}$ 12.890, de 10 de dezembro de 2013 (2013). Altera a Lei no 6.894, de 16 de dezembro de 1980, para incluir os remineralizadores como uma categoria de insumo destinado à agricultura e dá outras providencias. Diário Oficial da União, Brasília, DF, 10 dez 2013. http://www.planalto.gov.br/ccivil_03/_ato2011-2014/2013/lei/112890.htm

Brasil. Lei $n^{\circ} 12.305$ de 02 de agosto de 2010 (2010). Institui a Política Nacional de Resíduos Sólidos (PNRS). http://www.planalto.gov.br/c civil_03/_ato2007-2010/2010/lei/112305.htm

Brasil. Ministério da Agricultura, Pecuária e Abastecimento (MAPA). Instrução Normativa (IN) $n^{\circ} 05$ de 10 de março de 2016 (2016). Estabelece as regras sobre definições, classificação, especificações e garantias, tolerâncias, registro, embalagem, rotulagem e propaganda dos remineralizadores e substratos para plantas, destinados à agricultura. Diário Oficial da União, Brasília, DF, 10 jan 2016. https://www.in.gov.br/materia//asset_pu blisher/Kujrw0TZC2Mb/content/id/21393137/do1-2016-03-14-instrucao-normativa-n-5-de-10-de-marco-de-2016-21393106

Camargo, C. K., Resende, J. T. V., Camargo, L. K. P., Figueiredo, A. S. T. \& Zanin, D. S. (2012). Produtividade do morangueiro em função da adubação orgânica e com pó de basalto no plantio. Ciências Agrárias, 33(1), 2985-2993. https://www.redalyc.org/articulo.oa?id=445744117044

Carvalho, A. M. X., Cardoso I. M., Souza, M. E. P. \& Theodoro, S. H. (2018). Rochagem: O que se sabe sobre essa técnica? Solos e agroecologia; Coleção Transição Agroecológica. v. 4. Cardoso, I.M., Fávero, C. (Eds). Embrapa. 373. https://sgbeduca.cprm.gov.br/media/adultos/cartilha_rochagem.pdf

CPRM. Companhia de Pesquisa de Recursos Minerais (2020). Serviço Geológico do Brasil - CPRM e os ODS, Objetivos de Desenvolvimento Sustentável: agrogeologia.

Crusciol, C. A. C. \& Soratto, R. P. (2013). Eficiência de rocha fonolito moída como fonte de potássio para as culturas do arroz, feijão, milho e soja. Anais do II Congresso Brasileiro de Rochagem. 327-337. R. P. Theodoro, S. H., Martins, E. de S., Fernandes, M. M., Carvalho, A. M. X. de, (Eds) https://www.researchgate.net/publication/295099176_Anais_do_II_Congresso_Brasileiro_de_Rochagem_coletanea_de_varios_autores

EMBRAPA. Empresa Brasileira de Pesquisa Agropecuária (2020). VII Plano Diretor da Embrapa: 2020-2030. Brasília - DF.31p.

Instituto Brasil Orgânico (2021). Remineralizadores - Mapa de pós de rocha registrados no Ministério da Agricultura disponíveis no Brasil. https://institutobrasilorganico.org/atuacao/mapa-de-remineralizadores/ 
Research, Society and Development, v. 10, n. 14, e45101421516, 2021

(CC BY 4.0) | ISSN 2525-3409 | DOI: http://dx.doi.org/10.33448/rsd-v10i14.21516

MAPA. Ministério da Agricultura, Pecuária e Abastecimento (2021). Projeções do Agronegócio. Brasil: 2020/2021 a 2030/2031. Secretaria de Política Agrícola. 102.

MDIC. Ministério do Desenvolvimento da Indústria e Comércio (2021). Importação de adubos fertilizantes de jan a dez de 2020. http://comexstat.mdic.gov.br/pt/geral/41075.

MME. Ministério de Minas e Energia. Plano Nacional de Mineração 2030 (PNM - 2030) (2011) Brasília. 178 p. 1v http://antigo.mme.gov.br/web/gu est/secretarias/geologia-mineracao-e-transformacao-mineral/destaques-do-setor-de-energia/plano-nacional-de-mineracao-2030

Oliveira, M. P., Malagolli, G. A. \& Cella, D. (2019). Mercado de Fertilizantes: dependência de importações do Brasil. Revista Interface Tecnológica, 16 (1), 489-498. https://revista.fatectq.edu.br/index.php/interfacetecnologica/article/view/606

Piza, P. A. T., França, S. C. A. \& Bertolino, L. C. (2009). Verdete do Cedro de Abaeté (MG) como fonte alternativa para potássio. XVII Jornada de Iniciação Científica. Centro de Tecnologia Mineral - Cetem. http://dx.doi.org/10.1590/S1517-70762012000300004

Silva, D. W., Canepelle, E., Lanzanova, M. E. \& Guerra, D., Redin, M. (2020). Pó de basalto como fertilizante alternativo na cultura do feijão preto em Latossolo vermelho. Revista Verde de Agroecologia e Desenvolvimento Sustentável. 15 (4): 373-378. 10.18378 / rvads. v15i4.7784

Souza, F. N. S. (2014). O potencial de agrominerais silicáticos como fonte de nutrientes na agricultura tropical. Tese de Doutorado. Universidade de Brasília. http://dx.doi.org/10.26512/2014.12.T.18064

Theodoro, S. H. (2020). Cartilha da Rochagem. Ed. Ideal. https://www.researchgate.net/publication/344637113_Cartilha_da_Rochagem__The_Stonemeal_Guidebook

Theodoro, S. H. \& Leonardos, O. H. (2006). The use of rocks to improve family agriculture in Brazil. Anais da Academia Brasileira de Ciências, 78 (4). 721 730. https://doi.org/10.26848/rbgf.v5i6.232929

Theodoro, S. H., Tchouankou E, J. P., Gonçalves, A. O., Leonardos O. \& Harper J. (2012) A Importância de uma Rede Tecnológica de Rochagem para a Sustentabilidade em Países Tropicais. Revista Brasileira de Geografia Física. 5(.6). https://doi.org/10.26848/rbgf.v5i6.232929 